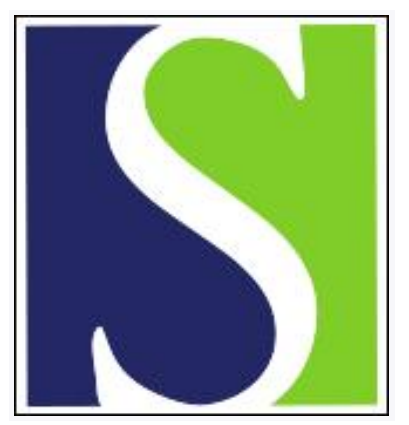

Scand J Work Environ Health 2011;37(4):298-306

https://doi.org/10.5271/sjweh.3148

Published online: 08 Feb 2011, Issue date: Jul 2011

Comparison of research case definitions for carpal tunnel syndrome

by Descatha A, Dale A-M, Franzblau A, Coomes J, Evanoff B

Affiliation: Division of General Medical Sciences, Washington University School of Medicine, St. Louis, MO, USA. adale@dom.wustl.edu

Refers to the following texts of the Journal: 2001;27(4):268-278 1997;23(4):299-307 1995;21(6):450-459 1999;25(2):115-124 2009;35(1):19-36

The following articles refer to this text: 2013;39(2):155-163; 2013;39(5):495-505

Key terms: carpal tunnel syndrome; case definition; median neuropathy; nerve conduction study; population study; screening

This article in PubMed: www.ncbi.nlm.nih.gov/pubmed/21301789

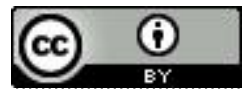




\title{
Comparison of research case definitions for carpal tunnel syndrome
}

\author{
by Alexis Descatha, MD, ${ }^{1,2}$ Ann-Marie Dale, PhD, ${ }^{2}$ Alfred Franzblau, MD, ${ }^{3}$ Justin Coomes, MD, ${ }^{2}$ \\ Bradley Evanoff, $M D^{2}$
}

\begin{abstract}
Descatha A, Dale A-M, Franzblau A, Coomes J, Evanoff B. Comparison of research case definitions for carpal tunne syndrome. Scand J Work Environ Health. 2011;37(4):298-306. doi:10.5271/sjweh.3148
\end{abstract}

\begin{abstract}
Objective The aim of this study was to assess agreement between different case definitions of carpal tunnel syndrome (CTS) for epidemiological studies.

Methods We performed a literature search for papers suggesting case definitions for use in epidemiological studies of CTS. Using data elements based on symptom questionnaires, hand diagrams, physical examinations, and nerve conduction studies collected from 1107 newly-hired workers, each subject in the study was classified according to each of the case definitions selected from the literature. We compared each case definition to every other case definition, using the Kappa statistic to measure pair-wise agreement on whether each subject met the case definition.
\end{abstract}

Results We found six unique papers in a 20-year period suggesting a case definition of CTS for use in population-based studies. We extracted seven case definitions. Definitions included different parameters: (i) symptoms only, (ii) symptoms and physical examination, (iii) symptoms and either physical examination or median nerve conduction study, and (iv) symptoms and nerve conduction study. When applied to our study population, the prevalence of CTS using different case definitions ranged from $2.5-11.0 \%$. The percentage of misclassification was between $1-10 \%$, with generally acceptable levels of agreement (kappa values ranged from $0.30-0.85$ ).

Conclusions Different case definitions resulted in widely varying prevalences of CTS. Agreement between case definitions was generally good, particularly between those that required very specific symptoms or the combination of symptoms and physical examination or nerve conduction. The agreement observed between different case definitions suggests that the results can be compared across different research studies of risk factors for CTS.

Key terms median neuropathy; nerve conduction study; population study; screening.

Carpal tunnel syndrome (CTS) is a common and costly disease among working-aged adults (1). Prevalence ranges from $1-5 \%$ among the general population and up to $14.5 \%$ among specific occupational groups $(1,2)$. Many studies of CTS have examined potential risk factors, preventive measures, and interventions. However, there is no "gold standard" for CTS diagnosis, nor is there consensus on the most appropriate research case definitions for CTS. Although case definitions in published studies have used some combination of symptoms, nerve conduction testing, and/or physical exam measures, they agree neither on what methods should be used nor on specific criteria or cut-points for testing (3). A recent systematic review of classification and case definitions of work-related upper-extremity disorders retrieved seven different case definitions of CTS (4). In a recent review that examined 44 papers dealing with the potential association between occupational exposure and CTS, a large variety of case definitions were described, and only 19 of these studies used a case definition that required both typical symptoms and electrodiagnostic examination (5).

Although there have been studies examining the sensitivity and specificity of individual case definitions $(6,7)$, or some element of these definitions $(8-10)$, these studies have not always been carried out in a general population or workplace settings, and the assessment of overlap between different case definitions has been

1 Université de Versailles St-Quentin-Inserm, UMRS 1018, Centre for Research in Epidemiology and Population Health, Epidemiology of Occupational and Social Determinants of Health, Occupational health Unit, Garches, France.

2 Division of General Medical Sciences, Washington University School of Medicine, St. Louis, MO, USA.

3 Department of Environmental Health Sciences, University of Michigan School of Public Health, Ann Arbor, MI, USA.

Correspondence to: Ann-Marie Dale, Division of General Medical Sciences, Washington University School of Medicine, St. Louis, MO, USA. [E-mail: adale@dom.wustl.edu] 
limited. As noted in a 1998 consensus case definition of CTS, the proliferation of case definitions can make it difficult to compare results across studies, and assessment of agreement of case definitions may facilitate comparisons between studies that employed different case definitions (11).

The objective of our study was to compare agreement between different case definitions of CTS for epidemiological research or population studies. We applied different case definitions of CTS to subjects in a large population of newly-hired adults and explored differences of case classification.

\section{Methods}

\section{General design}

We collected papers that specifically proposed cases definitions for CTS in epidemiological studies. The case definitions selected were applied to data from a study of newly-hired workers to evaluate the concordance of these different criteria.

\section{Literature review}

We searched for original papers dealing specifically with case definitions for CTS applicable to epidemiological studies. We searched in three databases: Pubmed, Embase, and Web of Science and reviewed references from selected papers for possible case definitions. Keywords used were "carpal tunnel syndrome" AND "case definition," "consensus definition," "diagnostic criteria," OR "case criteria." Our literature search included the 20 years between 1989 to early 2009 and was limited to English language and human subjects. Two independent reviewers read the identified papers. Inclusion required consensus that a paper clearly proposed a case definition of CTS for use in epidemiological studies.

\section{Quantitative analyses of the criteria used}

Subject recruitment and eligibility. To assess the concordance of results from the various case definitions, we used data from the Predicting Carpal Tunnel Syndrome (PrediCTS) study in St Louis, MO (12). Subjects were recruited from eight employers and three construction trade union apprenticeship programs in the Saint Louis area between July 2004 and October 2006. Subjects were eligible if they were $>18$ years and starting a new full-time job ( $>30$ hours per week) or changing their work benefits status. Subjects were excluded if they had a current or previous diagnosis of CTS or peripheral neuropathy, if they reported a contraindication to nerve conduction studies, or were pregnant. Recruitment occurred during employee orientations, new classes at apprenticeship programs, or at the time of employermandated post-offer, pre-placement screening, depending on the individual company or employer involved. The industries represented included manufacturing, construction, biotechnology, and healthcare. The Washington University School of Medicine and the University of Michigan Institutional Review Boards approved this study and all subjects provided written informed consent prior to participation.

Data collection. Subjects were tested at the time of enrollment in the study. Testing consisted of a selfadministered questionnaire, a physical examination of the upper extremities, and nerve conduction studies of both hands. All examiners were members of the research team that included an occupational physician, three occupational therapists, a physical therapy assistant, an occupational therapy assistant, and three medical students. Each examiner was instructed in a standardized physical examination testing procedure and demonstrated proficiency before collecting study data. Periodic re-evaluation of the examiners' performance was assessed over the course of the study.

Symptom definition. Symptoms of the hand and wrist were assessed with a self-administered questionnaire, using the following initial question: "In the past YEAR, have you had RECURRING (repeated) symptoms in your HANDS, WRISTS, or FINGERS more than 3 times or lasting more than ONE week?" If the response was yes, other questions asked about the location of symptoms (fingers, hands, wrists), the nature of the symptoms, and the presence of nocturnal symptoms. To clarify the localization and types of symptom, a Katz hand diagram was also completed by each subject reporting numbness, tingling, pain, or burning $(13,14)$. A team of three researchers (two physicians and an occupational therapist) independently rated each Katz hand diagram as "unlikely", "possible", "probable", or "classic" for CTS; disagreement between the reviewers was resolved by consensus (14).

Physical examination testing. The physical exam included inspection, Semmes-Weinstein sensory testing, Tinel's test, and Phalen's maneuver. In the SemmesWeinstein test, the examiner tested light touch sensation using a monofilament applied to the distal phalanx of the long finger of each hand. An abnormal response was the inability to detect touch with a \#2.83 monofilament at least two out of three times. For Tinel's test, the examiner tapped firmly over the median nerve from the palm of the hand to the proximal wrist. An abnormal response was recorded if the subject reported symptoms 
of paresthesia, burning, or numbness in the median nerve distribution. Phalen's maneuver required the subject to hold the wrists in full flexion for one minute by placing the backs of the hands together with the elbows raised to shoulder height. An abnormal response was recorded if the subject reported symptoms of paresthesia, burning, or numbness in the median nerve distribution.

Nerve conduction testing. Examiners performed median and ulnar nerve conduction studies at the wrist bilaterally using the NC-Stat nerve conduction testing device (NEUROMetrix, Inc, Waltham, MA). This clinical tool has been found to have reliability and criterion validity similar to traditional methods of nerve conduction testing $(15,16)$. Prior to data collection, all examiners demonstrated proficiency in use of the device following the standard testing procedures recommended by the manufacturer. The NC-Stat required placement of self-adhesive electrodes at the wrist and fingers using anatomic landmarks; the distance in centimeters between the wrist crease and the finger electrodes was measured as part of the testing protocol. We then measured median and ulnar distal motor latencies (wrist-thenar eminence and wrist-hypothenar eminence) and distal sensory latencies (wrist-third finger and wrist-fifth finger). Because the NC-Stat sensory electrodes are placed by reference to anatomic landmarks (the distal wrist crease and the finger crease of the proximal interphalangeal joint), the distance between the wrist and finger electrodes for median nerve measurements varied between 10.2-17.4 $\mathrm{cm}$ in our subjects. We normalized the measured sensory latencies for each subject to standard $14 \mathrm{~cm}$ sensory latencies using the measured nerve conduction velocity. We calculated median-ulnar sensory latency difference (MUDS) based on the $14 \mathrm{~cm}$-adjusted sensory latencies.

Abnormal median nerve conduction was defined in our study as either (i) a $14 \mathrm{~cm}$ sensory latency of the median nerve $>3.5 \mathrm{~ms}$, (ii) motor latency of the median nerve $>4.5 \mathrm{~ms}$, or (iii) paired transcarpal sensory difference [between median and ulnar nerves (MUD)] of $>0.5 \mathrm{~ms}$.

\section{Analyses}

To compare various definitions, we attempted to map all elements of each identified case definition to all subjects in our study. Each subject was classified separately for each case definition using the data elements collected in the study (ie, symptoms, hand diagrams, physical exams, and nerve conduction results). A subject was counted as a "case" of CTS for a particular case definition if the entire criteria were met within each arm, for either the right or the left hand. For instance, a subject with symptoms in the right hand but abnormal median nerve conduction values in left hand was not considered a "case"; a subject whose symptoms and abnormal median nerve conduction findings both occurred in the left hand was considered a "case". We calculated the prevalence of CTS using each case definition and compared concordance between the different definitions. We compared each case definition against every other definition as the "reference", and assessed intermethod agreement using the kappa statistic to measure pair-wise agreement on whether each subject met the case definition $(17,18)$. Values of kappa $>0.75$ are considered excellent, values between $0.40-0.75$ are fair-to-good, and values $<0.40$ represent poor agreement beyond chance alone (19). Because the prevalence of CTS was low, the kappa statistic may be low despite high agreement (20). To assess the "paradox" of low kappa values despite high agreement, we also report the true positive, false positive, true negative, and false negative rates, and the frequency of cases misclassified (21).

Statistical analysis software (SAS) version 8.2 (SAS Institute Inc, Cary, NC, USA) and statistical package for the social sciences (SPSS) version 11.01 (SPSS Inc, Chicago, IL, USA) were used for all analyses.

\section{Results}

\section{Literature review}

The literature review produced 324 papers based on the selection criteria and cross-references. Of these, 318 did not propose case definition criteria for CTS in epidemiological studies, or cited another reference already selected. Table 1 shows the six papers we found proposing case definitions for population-based studies (7, 11, 13, 22-24). One paper proposed 16 levels of case definition; we chose the most inclusive definition and the definition that had the greatest "accuracy" when compared to electrodiagnostic studies (best compromise between sensitivity and specificity) (7).

All of the definitions were different: two papers suggested a definition based on symptoms only, one on symptoms plus physical examination only, two required combinations of symptoms plus either physical exam or nerve conduction studies, and one required symptoms and nerve conduction studies. The symptoms criteria varied across definitions from non-specific hand symptoms (numbness, tingling, burning or pain in the hand, and nocturnal symptoms) to specific hand symptoms as described by the Katz hand diagram (13).

\section{Quantitative analyses of research case definitions}

The cohort included 435 apprentice construction workers, 478 hospital workers, 158 workers in computer or 
Table 1. Selected papers and case definition with the mapping for the Predicting Carpal Tunnel Syndrome (PrediCTS) study. [CTS=carpal tunnel syndrome]

\begin{tabular}{|c|c|c|c|}
\hline Author & Original criteria & $\begin{array}{l}\text { Type of items } \\
\text { used }\end{array}$ & PrediCTS mapping \\
\hline $\begin{array}{l}\text { Matte et al, } \\
1989 \text { (22) }\end{array}$ & $\begin{array}{l}\text { Symptoms suggestive of CTS are present. } \geq 1 \text { of the following symptoms are } \\
\text { sufficient: paresthesia, hypoesthesia, pain, or numbness affecting at least part } \\
\text { of the median nerve distribution of the hand(s). The median nerve distribution } \\
\text { generally includes palmar side of thumb, index finger, middle finger, and radial } \\
\text { half of ring finger; dorsal (back) side of same digits above proximal interpha- } \\
\text { langeal (PIP) joint; and radial half of palm. Pain and paresthesia may radiate } \\
\text { proximally into the arm. Symptoms should have lasted } \geq 1 \text { week or, if intermit- } \\
\text { tent, have occurred on multiple occasions. Other causes of hand numbness or } \\
\text { paresthesia, such as cervical radiculopathy, thoracic outlet syndrome, and pro- } \\
\text { nator teres syndrome, should be excluded by appropriate clinical evaluation. a }\end{array}$ & $\begin{array}{l}\text { Symptoms } \\
\text { AND } \\
\text { (physical exami- } \\
\text { nation abnor- } \\
\text { mality OR nerve } \\
\text { conduction } \\
\text { abnormality) }\end{array}$ & $\begin{array}{l}\text { One of the median innervated } \\
\text { fingers (digits } 1,2 \text {, or } 3 \text { ) is } \\
\text { shaded regardless of shading in } \\
\text { palm and back of hand (ie, hand } \\
\text { diagram coded as possible, } \\
\text { classic or probable a) } \\
\text { AND } \\
\text { (Tinel or Phalen signs, } \\
\text { sensory loss by using Semmes } \\
\text { Weinsteins test) }\end{array}$ \\
\hline
\end{tabular}

AND

Objective findings consistent with CTS are present in the affected hand(s) and wrist(s) EITHER: Physical examination findings. One or more of the following findings should be present: (i) Tinel's sign (paresthesia elicited or accentuated by gentle percussion over the carpal tunnel), (ii) present or positive Phalen's test (paresthesias are elicited or accentuated by maximal passive flexion of the wrist for one minute), or (iii) decreased or absent sensation to pin prick in the median nerve distribution of the hand OR Electrodiagnostic findings of median nerve dysfunction across the carpal tunnel. Criteria for abnormal electrodiagnostic findings are generally determined by the individual laboratories.

Katz et al, Katz hand diagram: classic or probable =tingling, numbness, burning, or de$1990(13)$ creased sensation with or without pain in $\geq 2$ of the digits 1,2 , or 3 . Palmar symptoms allowed if confined solely to the ulnar apect; $5^{\text {th }}$ finger symptoms, wrist pain or radiation proximal to the wrist allowed. If dorsal symptoms are present, classification is "possible."

Symptoms only

et al, 1993 (7)

Franzblau-2 Numbness, tingling, or pain in the hands or any finger) et al, 1993 (7) AND (nocturnal symptoms)

Harrington et Pain, or paraesthesia, or sensory loss in the median nerve distribution and one al, 1998 (23) of the following: Tinel's test positive, Phalen's test positive, nocturnal exacerbation of symptoms, motor loss with wasting of abductor pollicis brevis, and abnormal nerve conduction time.

Rempel et al, The combination of electrodiagnostic study findings and symptom charac$1998(11)$ teristics provides the most accurate CTS diagnosis. No single best scheme has emerged for assessing symptom qualities. A recommended classification scheme for symptoms based on Katz diagram (requires documentation of symptom location and character (numbness, tingling, burning, or pain). Electrodiagnostic studies should be performed according to the current and future guidelines prepared by the American Academy of Neurology, the American Association of Electrodiagnostic Medicine.

Sluiter et al, Symptoms present now or on $\geq 4$ days during the last 7 days

2001 (24) AND

Symptoms: intermittent paresthesias or pain in $\geq 2$ of digits 1,2 , or 3 ; may be present at night as well (allowing pain in the palm, wrist, or radiation proximal to the wrist)

AND

Signs: at least one of the following tests positive: flexion or carpal compressions test, Tinel's or Phalen's tests, two-point discrimination, or resisted thumb abduction or motor loss with wasting of abductor pollicis brevis muscle
Symptoms only

Symptoms only

Symptoms

AND

(nocturnal

symptoms OR

physical examination abnormality OR nerve conduction abnormality)

Symptoms

AND

nerve

conduction

abnormality

Symptoms

AND

physical

examination

abnormality
Katz hand diagram: classic or probable (ie, tingling, numbness, burning or pain in at least 2 of the digits 1, 2, or 3 ); symptoms in dorsum of hand excluded; wrist pain or radiation proximal to the wrist allowed palmar symptoms allowed.

Numbness, tingling, burning, or pain in the hands or any finger.

Numbness, tingling, burning or pain in the hands or any finger AND nocturnal symptoms.

Tingling, numbness, burning, or pain in $\geq 2$ of the digits 1,2 , or 3 AND

[(nocturnal exacerbation) OR physical examination positive (Tinel's, Phalen's test, inspection) OR nerve conduction study (abnormal)].

Katz hand diagram: classic or probable (ie, tingling, numbness, burning or pain in $\geq 2$ of the digits 1, 2, or 3. Symptoms in dorsum of hand excluded; wrist pain or radiation proxima to the wrist allowed, palmar symptoms allowed unless confined solely to the ulnar aspect. AND

nerve conduction study (abnormal).

Tingling, numbness, burning, or pain in $\geq 2$ of the digits 1,2 , or 3 AND

(Tinel's or Phalen's tests, Semmes Weinstein and inspection).

\footnotetext{
a In the validation study of the Matte et al (22) definition, the Katz hand diagram was used as the criteria for symptoms [possible, classic or probable by Katz hand diagram (6)]
} 
laboratory jobs, and 37 in other positions. There was wide variability in prior jobs reported, with 258 job titles (12). The study group was $65.1 \%$ male, with a mean age of 30.8 years [standard deviation (SD) 10.3] and a mean body mass index of 28.5 (SD 6.6). Ten subjects (1.0\%) had missing data in the symptoms, physical examination or nerve conduction studies, and were excluded from analyses.

A list of each of the definitions we selected and how we mapped their criteria to our methods can be found in table 1. Most of the parameters were easily mapped using data collected in our study. Exceptions included motor weakness of the abductor pollicis on physical examination, which was not tested in our study. Instead of motor weakness, we used muscle wasting on inspection (not found for any subject in our study). We tested sensory deficits using Semmes-Weinstein monofilaments instead of two-point discrimination as required by some criteria. Our symptom criteria required recurrent or persistent symptoms in the past year, which we substituted for the temporal requirement of symptoms in the Sluiter case definition ("symptoms present now or present on at least 4 days during the last 7 days"). Previous results have shown that "averaging" of symptom reporting over some period of time (eg, symptoms in the last 7 days, 30 days, or the last year) produces relatively stable results, and so our modification of the Sluiter case definition likely had only a small impact (25).

The prevalence of CTS varied from $2.5-11.0 \%$, depending on the case definition used (table 2). The case definitions requiring symptoms alone, in any part of the hand or fingers [Franzblau (1) and Franzblau (2)] resulted in the highest numbers of cases (table 3). The case definition requiring symptoms specific to the median nerve distribution plus electrodiagnostic abnormality [Rempel (11)] had the lowest number of cases, while those requiring symptoms plus physical exam or electrodiagnostic abnormality were intermediate. When each case definition was tested against all other case definitions, we found relatively small percentages of misclassification (1-10\%, table 4). The concordance using the Cohen's kappa statistic ranged from $0.30-0.81$. The greatest degree of misclassification $(>4.3 \%)$ and the lowest agreement measured by kappa $(<0.5)$ was seen when the least restrictive case definitions - those requiring only non-specific hand or finger symptoms were compared against case definitions requiring more specific hand symptoms (Katz hand diagram) and case definitions requiring symptoms plus physical examination or electrodiagnostic abnormality (figure 1). Use of a Katz hand diagram alone showed "good-to-excellent" agreement with case definitions requiring specific hand symptoms and physical examination or electrodiagnostic abnormality (kappa 0.64-0.80) when a Katz reading of probable or classic definition was required. Similar
Table 2. Frequency and proportion of clinical items (symptoms or physical examination), nerve conduction abnormality, using the selected case definitions in the Predicting Carpal Tunnel Syndrome (PrediCTS) study ( $\mathrm{N}=1097)$

\begin{tabular}{lrr}
\hline Clinical item & Frequency & $\%$ \\
\hline Symptoms of the hand and wrist & 121 & 11.0 \\
Night symptoms & 46 & 4.2 \\
Symptoms in $\geq 1$ digit (digits 1, 2, 3) & 83 & 7.6 \\
Symptoms in $\geq 2$ digits (digits 1, 2, 3) & 56 & 5.1 \\
Katz hand diagram: classic/probable rating & 41 & 3.7 \\
Semmes-Weinstein testing positive & 368 & 33.5 \\
Tinel's test positive & 178 & 16.2 \\
Phalen's test positive & 135 & 12.3 \\
Thenar wasting & 0 & 0.0 \\
Nerve conduction abnormality & 365 & 33.3 \\
\hline
\end{tabular}

Table 3. Frequency and proportion of carpal tunnel syndrome (CTS) using the selected case definitions in the Predicting Carpal Tunnel Syndrome (PrediCTS) study (N=1097) [PE=physical examination abnormality; NCS=nerve conduction study abnormality]

\begin{tabular}{llcc} 
Case definition & Type of items used & Frequency & $\%$ \\
\hline $\begin{array}{l}\text { Franzblau-1 et } \\
\text { al, } 1993 \text { (7) }\end{array}$ & Symptoms only & 121 & 11.0 \\
$\begin{array}{l}\text { Franzblau-2 et } \\
\text { al, } 1993 \text { (7) }\end{array}$ & Symptoms only & 75 & 6.8 \\
$\begin{array}{l}\text { Matte et al, } \\
1989(22)\end{array}$ & Symptoms and (PE or NCS ) & 72 & 6.6 \\
$\begin{array}{l}\text { Harrington et } \\
\text { al, } 1998(23)\end{array}$ & $\begin{array}{l}\text { Symptoms and (nocturnal } \\
\text { Katz et al, }\end{array}$ & 51 & 4.6 \\
$\begin{array}{l}\text { Sy90 (13) } \\
\text { Sluiter et al, }\end{array}$ & Symptoms or PE or NCS ) & & \\
$\begin{array}{l}\text { 2001 (24) } \\
\text { Rempel et al, }\end{array}$ & Symptoms and NCS & 41 & 3.7 \\
$1998(11)$ & & 40 & 3.6 \\
\hline
\end{tabular}

agreement was seen between case definitions requiring symptoms and physical examination or electro-diagnostic abnormality (kappa $0.70-0.81$ ). Slightly lower agreement was seen between a case definition that required symptoms and electrodiagnostic abnormality and those that allowed symptoms and physical examination (kappa $0.53-0.68)$.

\section{Discussion}

Different case definitions for CTS have been used in epidemiological studies, based on different combinations of symptoms, physical examination, and nerve conduction studies. When we tested different case definitions in the same study population, we found widely varying estimates of prevalence, yet a relatively high degree of 
Table 4. Concordance between the selected case definitions using the Predicting Carpal Tunnel Syndrome (PrediCTS) study data

\begin{tabular}{|c|c|c|c|c|c|c|c|c|}
\hline Tested criteria & Reference criteria & $\begin{array}{l}\text { True } \\
\text { positive }\end{array}$ & $\begin{array}{l}\text { False } \\
\text { positive }\end{array}$ & $\begin{array}{c}\text { False } \\
\text { negative }\end{array}$ & $\begin{array}{c}\text { True } \\
\text { negative }\end{array}$ & $\begin{array}{l}\text { Frequency } \\
\text { of misclass- } \\
\text { ification }\end{array}$ & $\%$ & kappa \\
\hline \multirow{6}{*}{$\begin{array}{l}\text { Franzblau-1 et al, } \\
1993(7)\end{array}$} & Franzblau-2 et al & 75 & 46 & 0 & 976 & 46 & 4.4 & 0.74 \\
\hline & Matte et al & 63 & 58 & 9 & 967 & 67 & 6.5 & 0.62 \\
\hline & Harrington et al & 44 & 77 & 7 & 969 & 84 & 8.3 & 0.48 \\
\hline & Katz et al & 35 & 86 & 6 & 970 & 92 & 9.2 & 0.40 \\
\hline & Sluiter et al & 35 & 86 & 5 & 971 & 91 & 9.0 & 0.40 \\
\hline & Rempel et al & 24 & 97 & 3 & 973 & 100 & 10.0 & 0.30 \\
\hline \multirow{6}{*}{$\begin{array}{l}\text { Franzblau-2 et al, } \\
1993(7)\end{array}$} & Franzblau-1 et al & 75 & 0 & 46 & 976 & 46 & 4.4 & 0.74 \\
\hline & Matte et al & 49 & 26 & 23 & 999 & 49 & 4.7 & 0.64 \\
\hline & Harrington et al & 36 & 39 & 15 & 1007 & 54 & 5.2 & 0.55 \\
\hline & Katz et al & 25 & 50 & 16 & 1006 & 66 & 6.4 & 0.40 \\
\hline & Sluiter et al & 26 & 49 & 14 & 1008 & 63 & 6.1 & 0.42 \\
\hline & Rempel et al & 19 & 56 & 8 & 1014 & 64 & 6.2 & 0.35 \\
\hline \multirow{6}{*}{$\begin{array}{l}\text { Matte et al ,1989 } \\
\text { (22) }\end{array}$} & Franzblau-1 & 63 & 9 & 58 & 967 & 67 & 6.5 & 0.62 \\
\hline & Franzblau-2 & 49 & 23 & 26 & 999 & 49 & 4.7 & 0.64 \\
\hline & Harrington et al & 46 & 26 & 5 & 1020 & 31 & 2.9 & 0.73 \\
\hline & Katz et al & 37 & 35 & 4 & 1021 & 39 & 3.7 & 0.64 \\
\hline & Sluiter et al & 40 & 32 & 0 & 1025 & 32 & 3.0 & 0.70 \\
\hline & Rempel et al & 27 & 45 & 0 & 1025 & 45 & 4.3 & 0.53 \\
\hline \multirow{6}{*}{$\begin{array}{l}\text { Harrington et al, } \\
1998 \text { (23) }\end{array}$} & Franzblau-1 et al & 44 & 7 & 77 & 969 & 84 & 8.3 & 0.48 \\
\hline & Franzblau-2 et al & 36 & 15 & 39 & 1007 & 54 & 5.2 & 0.55 \\
\hline & Matte et al & 46 & 5 & 26 & 1020 & 31 & 2.9 & 0.73 \\
\hline & Katz et al & 37 & 14 & 4 & 1042 & 18 & 1.7 & 0.80 \\
\hline & Sluiter et al & 37 & 14 & 3 & 1043 & 17 & 1.6 & 0.81 \\
\hline & Rempel et al & 27 & 24 & 0 & 1046 & 24 & 2.2 & 0.68 \\
\hline \multirow[t]{6}{*}{ Katz et al, 1990 (13) } & Franzblau-1 et al & 35 & 6 & 86 & 970 & 92 & 9.2 & 0.40 \\
\hline & Franzblau-2 et al & 25 & 16 & 50 & 1006 & 66 & 6.4 & 0.40 \\
\hline & Matte et al & 37 & 4 & 35 & 1021 & 39 & 3.7 & 0.64 \\
\hline & Harrington et al & 37 & 4 & 14 & 1042 & 18 & 1.7 & 0.80 \\
\hline & Sluiter et al & 30 & 11 & 10 & 1046 & 21 & 2.0 & 0.73 \\
\hline & Rempel et al & 27 & 14 & 0 & 1056 & 14 & 1.3 & 0.79 \\
\hline \multirow{6}{*}{$\begin{array}{l}\text { Sluiter et al, } 2001 \\
\text { (24) }\end{array}$} & Franzblau- 1 et al & 35 & 5 & 86 & 971 & 91 & 9.0 & 0.40 \\
\hline & Franzblau-2 et al & 26 & 14 & 49 & 1008 & 63 & 6.1 & 0.42 \\
\hline & Matte et al & 40 & 0 & 32 & 1025 & 32 & 3.0 & 0.70 \\
\hline & Harrington et al & 37 & 3 & 14 & 1043 & 17 & 1.6 & 0.81 \\
\hline & Katz et al & 30 & 10 & 11 & 1046 & 21 & 2.0 & 0.73 \\
\hline & Rempel et al & 20 & 20 & 7 & 1050 & 27 & 2.5 & 0.58 \\
\hline \multirow{6}{*}{$\begin{array}{l}\text { Rempel et al, } 1998 \\
\text { (11) }\end{array}$} & Franzblau-1 et al & 24 & 3 & 97 & 973 & 100 & 10.0 & 0.30 \\
\hline & Franzblau-2 et al & 19 & 8 & 56 & 1014 & 64 & 6.2 & 0.35 \\
\hline & Matte et al & 27 & 0 & 45 & 1025 & 45 & 4.3 & 0.53 \\
\hline & Harrington et al & 27 & 0 & 24 & 1046 & 24 & 2.2 & 0.68 \\
\hline & Katz et al & 27 & 0 & 14 & 1056 & 14 & 1.3 & 0.79 \\
\hline & Sluiter et al & 20 & 7 & 20 & 1050 & 27 & 2.5 & 0.58 \\
\hline
\end{tabular}




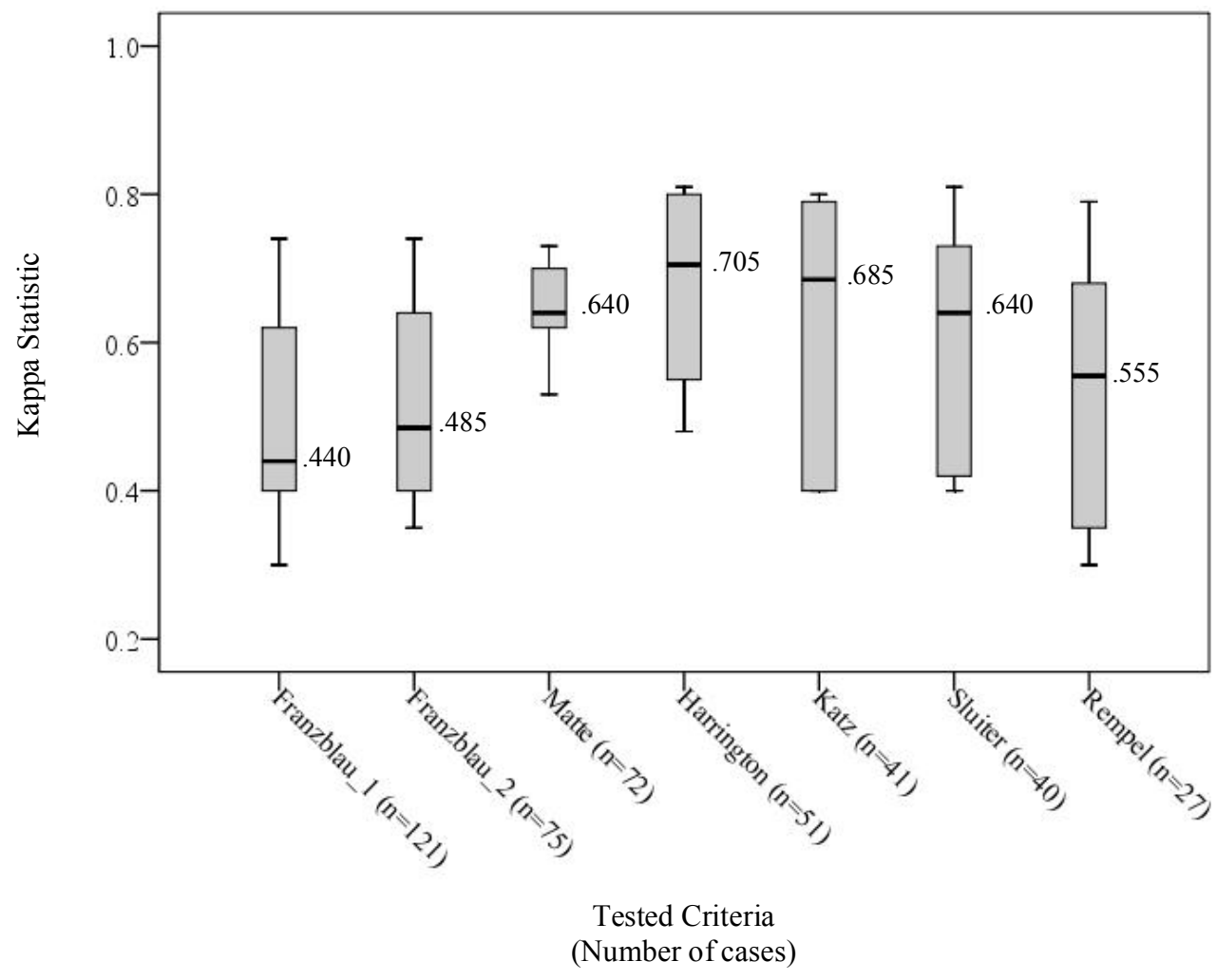

Figure 1. Distribution and median value of kappa values showing agreementbetween each case definition compared to all others tested $(\mathrm{N}=1107$, number of carpal tunnel syndrome cases mentioned below of each case definition). The top bar is the $95^{\text {th }}$ percentile, the top of the box is the $75^{\text {th }}$ percentile, the horizontal line in the box is the median, the bottom of the box is the $25^{\text {th }}$ percentile, and the bottom bar is the $5^{\text {th }}$ percentile. quantitative concordance between case definitions, with relatively low rates of misclassification.

Not surprisingly, definitions based on non-specific hand symptoms only led to the highest prevalence of disease, while more restrictive definitions requiring specific hand symptoms plus median nerve conduction abnormalities resulted in the lowest prevalence. Results of population surveillance studies are clearly sensitive to the case definition $(2,26)$. The proportion of misclassification between more restrictive and less restrictive case definition of CTS was relatively low.

The selection of the case definition papers was based on a literature search. We decided to include only those papers suggesting a case definition for use by other investigators, rather than testing the much larger group of different case definitions used in epidemiological studies $(3,5,27)$. We did not study definitions based on insurance or medical treatment claims of CTS nor self-reports of treatment or diagnosis, though such case definitions are useful for some surveillance and epidemiological studies (28-31). We believe that our choice of case definitions is representative of the spectrum of definitions that have been used.

One limitation of our study approach could be in the mapping of our study data to the case definitions described in the literature. When authors described a symptom or a sign not recorded in the study, we selected the closest item in our study. Only a few items were different: motor loss in physical examination, choice of sensory examination, and the time period for symptoms in the Sluiter et al (24) case definition. The Sluiter time period, that incorporates a timeframe, frequency and duration, were included in their document in order to differentiate common aches and pain from work-related musculoskeletal disorders, and did not serve to define the type of the disease. As noted earlier, the difference in timeframes between Sluiter and our study probably made only minor differences in the prevalence of CTS. Motor loss in our study was evaluated by inspection (thenar atrophy). The study was based on screening a large population for clinically unreported CTS and no atrophy was found, which is not surprising. In a study of active workers, the prevalence of motor loss corresponding to severe CTS is expected to be low, even if assessed by physical examination of motor strength. Different results might be seen in a clinical population with a higher prevalence and greater severity of CTS (32).

Another potential limitation of our study was our definition of abnormal median nerve conduction. In both clinical settings and population studies, the determination of normative values for nerve conduction is complicated, with different possible cut-offs depending on the studies' purposes $(11,33,34)$. None of the case definitions selected from the literature defined cut-off points for 
nerve conduction. We chose nerve conduction cut-offs that have been proposed for use in a large multicenter study of CTS in working populations, and applied these same criteria to all case definitions. More stringent criteria for abnormality may have resulted in slightly different study results, with fewer subjects rated as abnormal (33).

Our study compared concordance between different case definitions, but did not propose a "best" case definition for CTS - even in clinical settings, there is no gold standard for establishing a diagnosis of CTS $(35,36)$. Different authors have described different methods to study the clinical diagnosis of CTS, with different results (35, 37-42). We could conclude some definitions are more conservative than others. Their use depends on the purpose of the study and their feasibility (43). We found a fair degree of agreement between different case definitions in a general working population. These results suggest that comparison of risk factors for CTS across studies may not be greatly biased by misclassification errors due to differences in case definitions of CTS, though it is important to note that the prevalence of disease is likely to be different when using different case definitions.

\section{Acknowledgements}

This study was supported by research funding from the Centers for Disease Control / National Institute of Occupational Safety and Health (R01 OH008017-01) and from the National Center for Research Resources (NCRR), a component of the National Institutes of Health (NIH), and NIH Roadmap for Medical Research (UL1 RR024992). Financial support for Justin Coomes was provided by the Doris Duke Charitable Foundation.

\section{References}

1. Atroshi I, Gummesson C, Johnsson R, Ornstein E, Ranstam J, Rosen I. Prevalence of carpal tunnel syndrome in a general population. JAMA. 1999;282:153-8.doi:10.1001/ jama.282.2.153.

2. Roquelaure Y, Ha C, Pelier-Cady MC, Nicolas G, Descatha A, Leclerc A, et al. Work increases the incidence of carpal tunnel syndrome in the general population. Muscle Nerve. 2008;37:477-82. doi:10.1002/mus.20952.

3. Bonfiglioli R, Mattioli S, Violante FS. Relationship between symptoms and instrumental findings in the diagnosis of upper limb work-related musculoskeletal disorders. Med Lav. 2007;98:118-26.

4. Boocock MG, Collier JM, McNair PJ, Simmonds M, Larmer PJ, Armstrong B. A framework for the classification and diagnosis of work-related upper extremity conditions: systematic review. Semin Arthritis Rheum. 2009;38:296-311.

doi:10.1016/j.semarthrit.2007.10.006

5. van Rijn RM, Huisstede BM, Koes BW, Burdorf A. Associations between work-related factors and the carpal tunnel syndrome--a systematic review. Scand J Work Environ Health. 2009;35:19-36.

6. Katz JN, Larson MG, Fossel AH, Liang MH. Validation of a surveillance case definition of carpal tunnel syndrome. Am J Public Health. 1991;81:189-93. doi:10.2105/AJPH.81.2.189

7. Franzblau A, Flaschner D, Albers JW, Blitz S, Werner R, Armstrong T. Medical screening of office workers for upper extremity cumulative trauma disorders. Arch Environ Health. 1993;48:164-70. doi:10.1080/00039896.1993.9940815.

8. Homan MM, Franzblau A, Werner RA, Albers JW, Armstrong TJ, Bromberg MB. Agreement between symptom surveys, physical examination procedures and electrodiagnostic findings for the carpal tunnel syndrome. Scand J Work Environ Health. 1999;25:115-24.

9. Isolani L, Bonfiglioli R, Raffi GB, Violante FS. Different case definitions to describe the prevalence of occupational carpal tunnel syndrome in meat industry workers. Int Arch Occup Environ Health. 2002;75:229-34. doi:10.1007/s00420-0010304-2.

10. Descatha A, Dale AM, Franzblau A, Coomes J, Evanoff B. Diagnostic strategies using physical examination are minimally useful in defining carpal tunnel syndrome in population-based research studies. Occup Environ Med. 2010;67(2):133-5. doi:10.1136/oem.2009.047431.

11. Rempel D, Evanoff B, Amadio PC, de Krom M, Franklin G, Franzblau A, et al. Consensus criteria for the classification of carpal tunnel syndrome in epidemiologic studies. Am J Public Health. 1998;88:1447-51. doi:10.2105/AJPH.88.10.1447.

12. Armstrong TN, Dale AM, Franzblau A, Evanoff B. Risk Factors for Carpal Tunnel Syndrome and Median Neuropathy in a Working Population. J Occup Environ Med. 2008;50:1355-64. doi:10.1097/JOM.0b013e3181845fb1.

13. Katz JN, Stirrat CR, Larson MG, Fossel AH, Eaton HM, Liang MH. A self-administered hand symptom diagram for the diagnosis and epidemiologic study of carpal tunnel syndrome. J Rheumatol. 1990;17:1495-8.

14. Dale AM, Strickland J, Symanzik J, Franzblau A, Evanoff B. Reliability of hand diagrams for the epidemiologic case definition of carpal tunnel syndrome. J Occup Rehabil. 2008;18:233-48. doi:10.1007/s10926-008-9139-y.

15. Kong X, Gozani SN, Hayes MT, Weinberg DH. NCstat sensory nerve conduction studies in the median and ulnar nerves of symptomatic patients. Clin Neurophysiol. 2006;117:405-13. doi:10.1016/j.clinph.2005.10.019.

16. Armstrong TN, Dale AM, Al Lozi MT, Franzblau A, Evanoff BA. Median and ulnar nerve conduction studies at the wrist: criterion validity of the NC-stat automated device. J Occup Environ Med. 2008;50:758-64. doi:10.1097/ JOM.0b013e3181645425.

17. Chmura Kraemer H, Periyakoil VS, Noda A. Kappa coefficients in medical research. Stat Med. 2002;21:2109-29. doi:10.1002/sim.1180. 
18. Tooth LR, Ottenbacher KJ. The [kappa] statistic in rehabilitation research: An examination. Archives of Physical Medicine and Rehabilitation. 2004;85:1371-6. doi:10.1016/j. apmr.2003.12.002.

19. Fleiss JL. Statistical methods for rates and proportions. 2 ed. New York: John Wiley; 1981.

20. Hulley SB, Cummings SR, Browner WS, et al. Designing Clinical Research: An Epidemiologic Approach. Second edition. Philadelphia: Lippincott Williams \& Wilkins; 2001.

21. Lantz CA, Nebenzahl E. Behavior and interpretation of the kappa statistic: resolution of the two paradoxes. J Clin Epidemiol. 1996;49:431-4. doi:10.1016/0895-4356(95)00571-4.

22. Matte TD, Baker EL, Honchar PA. The selection and definition of targeted work-related conditions for surveillance under SENSOR. Am J Public Health. 1989;79 Suppl:21-5. doi:10.2105/AJPH.79.Suppl.21.

23. Harrington JM, Carter JT, Birrell L, Gompertz D. Surveillance case definitions for work related upper limb pain syndromes. Occup Environ Med. 1998;55:264-71. doi:10.1136/ oem.55.4.264.

24. Sluiter JK, Rest KM, Frings-Dresen MH. Criteria document for evaluating the work-relatedness of upper-extremity musculoskeletal disorders. Scand J Work Environ Health. 2001;27 Suppl 1:1-102.

25. Franzblau A, Salerno DF, Armstrong TJ, Werner RA. Test-retest reliability of an upper-extremity discomfort questionnaire in an industrial population. Scand J Work Environ Health. 1997;23:299-307.

26. Davis L, Wellman H, Punnett L. Surveillance of work-related carpal tunnel syndrome in Massachusetts, 1992-1997: a report from the Massachusetts Sentinel Event Notification System for Occupational Risks (SENSOR). Am J Ind Med. 2001;39:58 71. doi:10.1002/1097-0274(200101)39:1<58::AIDAJIM6>3.0.CO;2-3.

27. Marx RG, Bombardier C, Wright JG. What do we know about the reliability and validity of physical examination tests used to examine the upper extremity? J Hand Surg [Am]. 1999;24:185-93. doi:10.1053/jhsu.1999.jhsu24a0185.

28. Silverstein BA, Stetson DS, Keyserling WM, Fine LJ. Work-related musculoskeletal disorders: comparison of data sources for surveillance. Am J Ind Med. 1997;31:600-8. doi:10.1002/(SICI)1097-0274(199705)31:5<600::AIDAJIM15>3.0.CO;2-2.

29. Dell'Omo M, Murgia N, Gambelunghe A, Muzi G. Clinical and diagnostic features of upper extremity work-related musculoskeletal disorders. Med Lav. 2006;97:542-9.

30. Leclerc A, Landre MF, Chastang J-F, Niedhammer I, Roquelaure Y. Upper-limb disorders in repetitive work. Scand J Work Environ Health. 2001;27:268-78.

31. Nordstrom DL, Vierkant RA, DeStefano F, Layde PM. Risk factors for carpal tunnel syndrome in a general population.
Occup Environ Med. 1997;54:734-40. doi:10.1136/ oem.54.10.734.

32. Bonauto DK, Silverstein BA, Fan ZJ, Smith CK, Wilcox DN. Evaluation of a symptom diagram for identifying carpal tunnel syndrome. Occup Med (Lond). 2008;58:561-6. doi:10.1093/ occmed/kqn123.

33. Salerno DF, Franzblau A, Werner RA, Bromberg MB, Armstrong TJ, Albers JW. Median and ulnar nerve conduction studies among workers: normative values. Muscle Nerve. 1998;21:999-1005. doi:10.1002/(SICI)10974598(199808)21:8<999::AID-MUS3>3.0.CO;2-0.

34. Atroshi I, Gummesson C, Johnsson R, Ornstein E. Diagnostic properties of nerve conduction tests in population-based carpal tunnel syndrome. BMC Musculoskelet Disord. 2003;4:9. doi:10.1186/1471-2474-4-9.

35. Graham B, Regehr G, Naglie G, Wright JG. Development and validation of diagnostic criteria for carpal tunnel syndrome. J Hand Surg [Am]. 2006;31:919-24. doi:10.1016/j. jhsa.2006.03.005.

36. Franzblau A, Werner RA. What is carpal tunnel syndrome? JAMA. 1999;282:186-7. doi:10.1001/jama.282.2.186.

37. Wainner RS, Fritz JM, Irrgang JJ, Delitto A, Allison S, Boninger ML. Development of a clinical prediction rule for the diagnosis of carpal tunnel syndrome. Arch Phys Med Rehabil. 2005;86:609-18. doi:10.1016/j.apmr.2004.11.008.

38. de Krom MC, Knipschild PG, Kester AD, Spaans F. Efficacy of provocative tests for diagnosis of carpal tunnel syndrome. Lancet. 1990;335:393-5. doi:10.1016/01406736(90)90218-T.

39. Szabo RM, Slater RR, Jr., Farver TB, Stanton DB, Sharman WK. The value of diagnostic testing in carpal tunnel syndrome. J Hand Surg [Am]. 1999;24:704-14. doi:10.1053/ jhsu.1999.0704

40. Massy-Westropp N, Grimmer K, Bain G. A systematic review of the clinical diagnostic tests for carpal tunnel syndrome. J Hand Surg Am. 2000;25:120-7. doi:10.1053/jhsu.2000. jhsu025a0120.

41. D'Arcy CA, McGee S. The rational clinical examination. Does this patient have carpal tunnel syndrome? JAMA. 2000;283:3110-7.

42. Helliwell PS, Bennett RM, Littlejohn G, Muirden KD, Wigley $\mathrm{RD}$. Towards epidemiological criteria for soft-tissue disorders of the arm. Occup Med (Lond). 2003;53:313-9. doi:10.1093/ occmed/kqg034.

43. Coggon D, Martyn C, Palmer KT, Evanoff B. Assessing case definitions in the absence of a diagnostic gold standard. Int J Epidemiol. 2005;34:949-52. doi:10.1093/ije/dyi012

Received for publication: 25 October 2010 